\title{
UM EXPERIMENTO-CHARADA USANDO DATA-SHOW E RESINAS DE TROCA IÔNICA
}

\author{
Viktoria Klara Lakatos Osorio, Miuaco Kawashita Kuya, Alessandra de Souza Maia e Wanda de Oliveira* \\ Instituto de Química, Universidade de São Paulo, CP 26077, 05513-970 São Paulo - SP
}

Recebido em 30/10/02; aceito em 20/3/03

\begin{abstract}
A QUIZ-EXPERIMENT USING DATA-SHOW AND ION EXCHANGE RESINS. A demonstractive experiment was proposed in order to verify students' habilities in recognizing the presence and nature of ions in solutions, before and after their passage through ion-exchange columns. The students have no previous contact with ion-exchange resins, so they must deduce how they work and explain the experimental facts. The performance of classes, at different stages of learning, is compared and discussed.
\end{abstract}

Keywords: ion exchange resins; water deionization; ion exchange equilibrium.

\section{INTRODUÇÃO}

A Olimpíada de Química SP-2002, dirigida a estudantes do ensino médio (antigo segundo grau), teve como tema "Água: purificação química e uso racional". Os 100 candidatos selecionados, na primeira fase, com base numa redação sobre o tema, foram convocados para a fase final, que constou de uma prova de conhecimento e raciocínio, realizada no Instituto de Química da USP, em 8 de junho de $2002^{1}$. Os 20 melhores colocados no vestibular da FUVEST na categoria de "treineiros" também foram chamados. Nesta prova, os estudantes assistiram a alguns experimentos de química e, em segui$\mathrm{da}$, responderam às questões propostas na forma de um relatório dirigido.

Um dos experimentos realizados versou sobre tratamento de água usando dois tipos de resinas de troca iônica. Os estudantes receberam um mínimo de informações sobre as resinas, para que pudessem, com base nos fatos observados, deduzir os processos de equilíbrios ocorridos nas colunas de resina.

O experimento foi depois aplicado em uma disciplina de Química Inorgânica para alunos do segundo semestre do curso de Farmácia-Bioquímica da Faculdade de Ciências Farmacêuticas, USP. Esses alunos já haviam cursado uma disciplina de Química Geral, no semestre anterior, onde estudaram soluções eletrolíticas e equilíbrios químicos em solução aquosa, porém não fenômenos de troca iônica.

Os desempenhos dos dois grupos de estudantes são comentados e comparados, neste artigo. As resinas de troca iônica prestam-se bem ao tipo de atividade desenvolvida, que visa avaliar a capacidade de observação e dedução, pois elas não são familiares aos alunos do ensino médio e do primeiro ano universitário. Equilíbrios de troca iônica usualmente não são abordados nestas etapas da formação escolar, embora sejam fenômenos muito difundidos na natureza e de importância indiscutível.

O reconhecimento do fenômeno de troca iônica é geralmente atribuído aos químicos agrícolas ingleses, H. S. Thompson e J. T. Way, em $1850^{2-4}$, que investigavam propriedades de solo, porém as referências sobre a utilização do processo são muito mais antigas. Um exemplo curioso é a passagem bíblica (Exodus 15:25) em que Moisés, conduzindo o povo israelita através do deserto, converteu

*e-mail: wdolivei@iq.usp.br água amarga em água doce utilizando galhos de uma árvore, o que poderia ser interpretado como efeito da ação trocadora de íons exercida pela celulose oxidada presente na madeira ${ }^{3,5}$. As inumeráveis citações sobre purificação de água do mar, usando solos e argilas, remontam aos tempos de Aristóteles, quatro séculos A.C. ${ }^{3,5}$. São conhecidos há muito tempo, materiais inorgânicos e orgânicos, tanto naturais como sintéticos, com a capacidade de trocar íons.

\section{INSTRUÇÕES E DEMONSTRAÇÕES}

Os alunos receberam um roteiro, reproduzido abaixo, contendo algumas informações preliminares, instruções sobre o procedimento experimental e espaço para anotações.

\section{Informações}

- O indicador universal utilizado é constituído de uma mistura de corantes que permite avaliar o $\mathrm{pH}$ no intervalo de 1 a 10, através da variação de cor.

- A presença de íons numa solução pode ser verificada mergulhando nela um par de eletrodos, em série com uma lâmpada ligada a uma fonte de tensão.

- Resinas trocadoras de íons são materiais porosos e insolúveis, geralmente sob a forma de pérolas, que têm a capacidade de trocar íons. São constituídas de matrizes orgânicas ou inorgânicas em que se encontram fixos íons (positivos ou negativos) e para manter a neutralidade devem conter contra-íons móveis ou deslocáveis, de carga oposta.

- O líquido que atravessou uma coluna de resina é chamado de líquido eluído.

\section{Parte I - Investigação sobre as resinas A e B}

(a) Observe as soluções de $\mathrm{K}_{2} \mathrm{SO}_{4}\left(0,2 \mathrm{~mol} \mathrm{~L}^{-1}\right), \mathrm{CuSO}_{4}\left(0,4 \mathrm{~mol} \mathrm{~L}^{-1}\right)$ e $\mathrm{K}_{2} \mathrm{Cr}_{2} \mathrm{O}_{7}\left(0,04 \mathrm{~mol} \mathrm{~L}^{-1}\right)$.

(b) Misture volumes iguais de soluções de $\mathrm{CuSO}_{4}$ e $\mathrm{K}_{2} \mathrm{Cr}_{2} \mathrm{O}_{7}$. Anote suas observações. Ocorreu ou não uma reação química?

(c) Coloque em um tubo de ensaio um pouco da solução de $\mathrm{CuSO}_{4}$ e introduza o tubo de ensaio num béquer contendo solução de $\mathrm{K}_{2} \mathrm{Cr}_{2} \mathrm{O}_{7}$. Compare a sua observação com a do item anterior. Você mantém a sua resposta a respeito da ocorrência de reação?

(d) Passe a solução obtida no item (b) por uma coluna de resina A. 
(e) Verifique o pH e a cor do líquido eluído.

(f) Passe o líquido eluído da resina A por uma coluna de resina B.

(g) Verifique o $\mathrm{pH}$ e a cor do líquido eluído.

(h) Passe uma solução de $\mathrm{H}_{2} \mathrm{SO}_{4}\left(4,0 \mathrm{~mol} \mathrm{~L}^{-1}\right)$ pela coluna de resina A utilizada no item (d) e observe o líquido eluído.

(i) Passe uma solução de $\mathrm{NaOH}\left(4,0 \mathrm{~mol} \mathrm{~L}^{-1}\right)$ pela coluna de resina B utilizada no item (f) e observe o líquido eluído.

Esta parte do experimento, utilizando soluções coloridas, baseiase numa proposta feita por Kuya e Osorio ${ }^{6}$ e foi apresentada em data-show. As imagens referentes às etapas (a), (b) e (c) estão reunidas na Figura 1 e as etapas (d) até (g) estão na Figura 2. A Figura 3 ilustra as etapas (h) e (i).
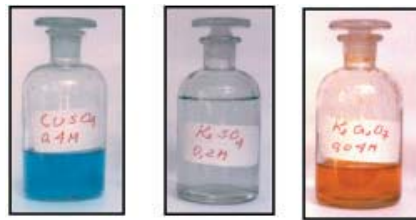

a)

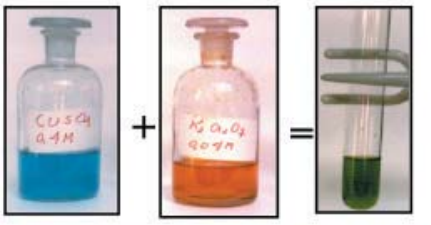

b)

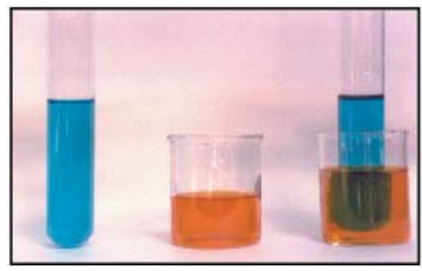

c)

Figura 1. Identificação das espécies coloridas nas soluções (etapas (a), (b) $e$ (c) da parte I do experimento)

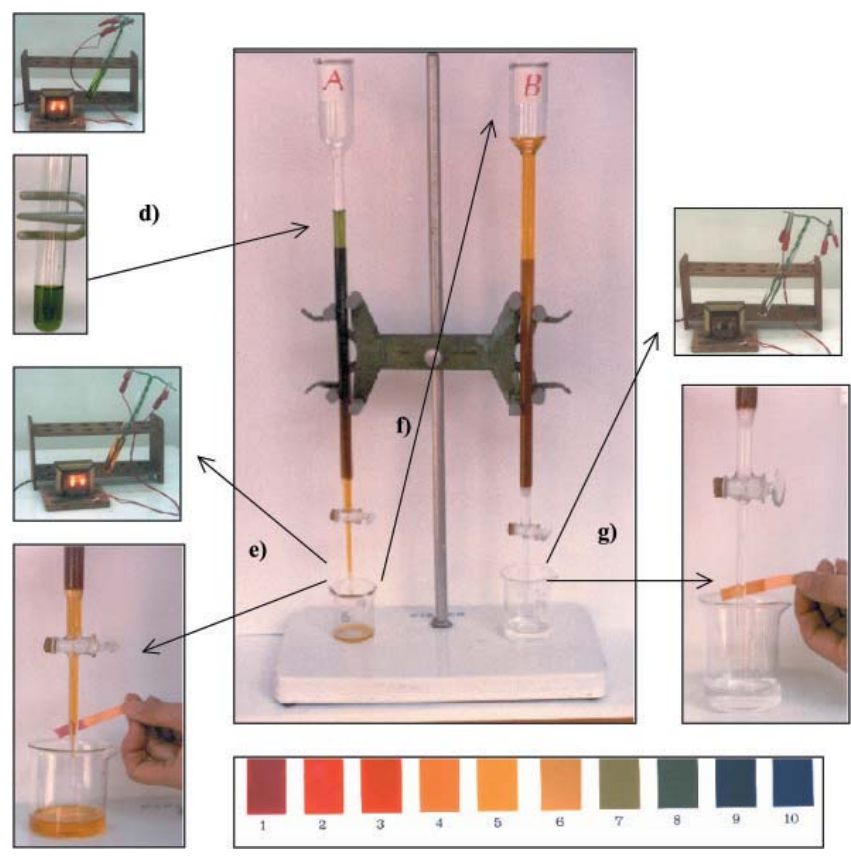

Figura 2. Investigação sobre as resinas A e B (etapas (d) a ( $g$ ) da parte I do experimento)
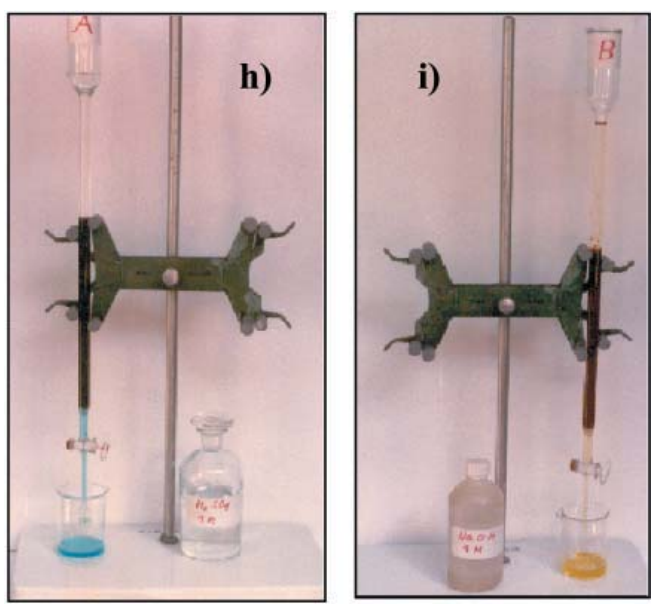

Figura 3. Regeneração das resinas A e B (etapas $(h)$ e (i) da parte I do experimento)

\section{Parte II - Purificação de água utilizando as resinas A e B}

(a) Verifique com papel indicador universal o $\mathrm{pH}$ da água a ser purificada.

(b) Verifique a condutividade da água a ser purificada.

(c) Passe pela coluna de resina A, cerca de $20 \mathrm{~mL}$ da água a ser purificada.

(d) Recolha o líquido eluído em um béquer de $150 \mathrm{~mL}$ limpo.

(e) Verifique o $\mathrm{pH}$ do líquido eluído da coluna de resina $\mathrm{A}$.

(f) Verifique a condutividade do líquido eluído da coluna de resina A.

(g) Passe o líquido eluído da coluna de resina A pela coluna de resina B.

(h) Verifique o $\mathrm{pH}$ do líquido eluído da coluna de resina B.

(i) Verifique a condutividade do líquido eluído da coluna de resina B. Esta parte do experimento foi efetuada sob a forma de demonstrações para os participantes da Olimpíada e apresentada em datashow para os alunos da Faculdade de Ciências Farmacêuticas. As imagens podem ser visualizadas na Figura 4.

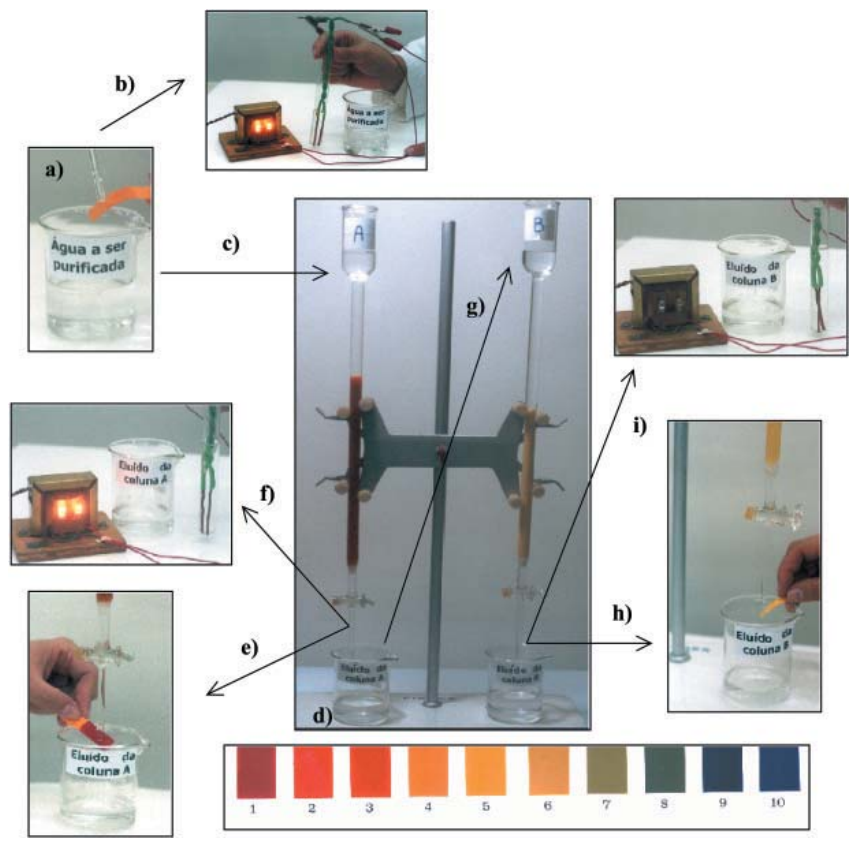

Figura 4. Purificação de água utilizando as resinas A e B (parte II do experimento) 


\section{RELATÓRIO DE AVALIAÇÃO}

Após assistirem às demonstrações das experiências, os alunos receberam um formulário de relatório dirigido, apresentado a seguir, que foi preenchido com consulta às anotações efetuadas. Os alunos do ensino superior foram informados de que o relatório não receberia nota e não foi solicitada identificação. Neste relatório foi também perguntado se os estudantes já conheciam as propriedades das resinas de troca iônica e, em caso afirmativo, onde adquiriram este conhecimento.

\section{Relatório - Purificação de Água - Tratamento com resinas trocadoras de íons}

1 - Interpretação da investigação sobre as resinas A e B

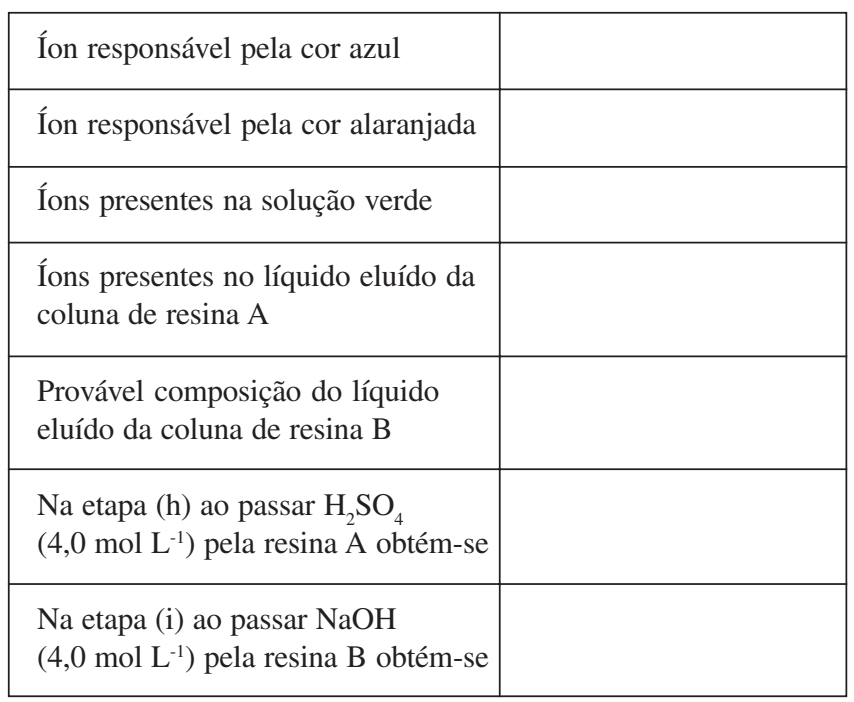

2 - Descreva as suas observações sobre a água impura, o líquido eluído da resina $\mathrm{A}$ e o líquido eluído da resina $\mathrm{B}$ quanto à passagem da corrente elétrica.

3 - Explique os valores de $\mathrm{pH}$ obtidos na água impura, no líquido eluído da resina A e no líquido eluído da resina $\mathrm{B}$.

4 - Que tipo de impureza pode ser removida pelo tratamento com as resinas A e B?

5 - Após purificação de muita água, como ficam as resinas? Como elas podem ser recuperadas para purificar mais água?

\section{DESEMPENHO DOS ESTUDANTES}

Compareceram às provas finais da Olimpíada de Química SP200253 alunos do $2^{\circ}$ ano e 55 alunos do $3^{\circ}$ ano do ensino médio. Destes alunos, 2 do $2^{\circ}$ ano e 5 do $3^{\circ}$ ano declararam ter conhecimento prévio sobre resinas de troca iônica, obtido em curso técnico ou durante a pesquisa na literatura para a elaboração da redação, na primeira fase da Olimpíada.

Os alunos da FCF, USP, que participaram da atividade, totalizaram 77 no período diurno e 68, no noturno. Dentre eles, 3 alunos do diurno e 9 do noturno já conheciam resinas, por provirem de cursos técnicos ou por utilização no trabalho.

$\mathrm{Na}$ discussão que se segue, para maior simplicidade, estes quatro conjuntos de alunos, a saber, $2^{\circ}$ e $3^{\circ}$ anos do ensino médio e períodos diurno e noturno da $\mathrm{FCF}$, serão designados por $2^{\circ}$ ano, $3^{\circ}$ ano, FD e FN, respectivamente.

\section{Parte I - Investigação sobre as resinas A e B}

As questões referentes à identificação dos íons presentes na soluções azul, alaranjada e verde (Figura 1) indicaram que os alunos do ensino superior apresentam maior facilidade em identificar os íons presentes em uma solução e escrever corretamente as fórmulas correspondentes, conforme ilustra o levantamento dos índices de acerto, representados comparativamente na Figura 5.

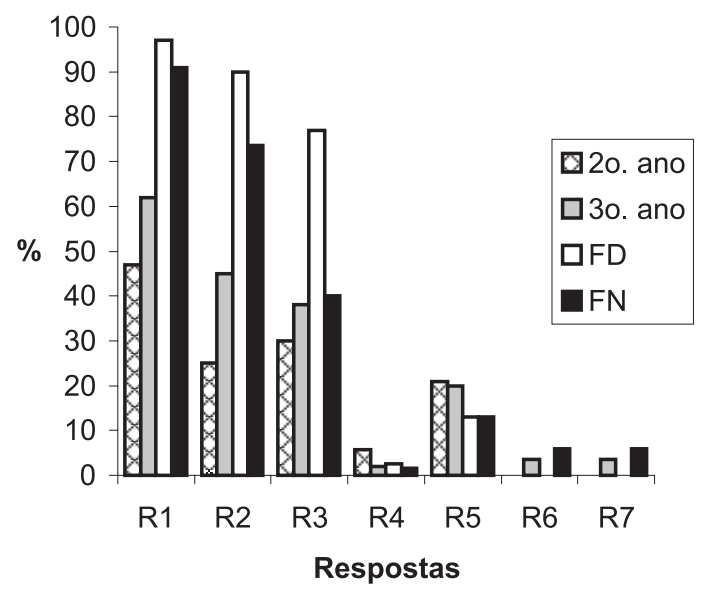

Figura 5. Desempenho dos alunos nas questões sobre a parte I do experimento: $R 1=$ ion responsável pela cor azul; $R 2=i o n$ responsável pela cor alaranjada; $R 3=$ ions presentes na solução verde $; R 4=$ ions presentes no eluído da resina $A ; R 5$ = composição provável do eluído da resina $B ; R 6=$ passagem de $\mathrm{H}_{2} \mathrm{SO}_{4}$ pela resina $A ; R 7=$ passagem de $\mathrm{NaOH}$ pela resina $B$

Esta diferença de desempenho pode estar associada a uma melhor compreensão do que ocorre ao se dissolver um sólido iônico em água e ao reconhecimento das evidências de ocorrência ou não de uma reação química, assuntos abordados no início do curso superior.

Excetuando-se os alunos da turma FD, a porcentagem de acerto foi bem menor na identificação do íon responsável pela cor alaranjada $\left(\mathrm{Cr}_{2} \mathrm{O}_{7}^{2-}\right)$ do que do íon responsável pela cor azul $\left(\mathrm{Cu}^{2+}\right)$. Isto mostra a dificuldade dos alunos com relação à fórmula do íon dicromato. Notou-se que, com poucas exceções, os mesmos alunos representaram corretamente o íon $\mathrm{SO}_{4}{ }^{2-}$, com o qual evidentemente estão mais habituados. Diversos alunos (15\% do $2^{\circ}$ ano, $7 \%$ do $3^{\circ}$ ano e $13 \%$ da FN) representaram a espécie contendo cromo como uma espécie monoatômica com cargas variadas $\left(\mathrm{Cr}^{2+}, \mathrm{Cr}^{6+}, \mathrm{Cr}^{7+}\right.$ e até $\left.\mathrm{Cr}^{2-}\right)$, revelando uma confusão entre os conceitos de íons e de estados de oxidação e dificuldade na atribuição destes últimos.

A questão referente à identificação dos íons presentes na solução verde, obtida pela mistura das soluções de sulfato de cobre e de dicromato de potássio, mostrou que muitos alunos não estão acostumados a interpretar corretamente as informações disponíveis, restringindo-se mais ao aspecto visual do sistema. Parcelas iguais a $11 \%$ ( $2^{\circ}$ ano), $16 \%$ ( $3^{\circ}$ ano), $5 \%$ (FD) e $47 \%$ (FN) dos estudantes citaram apenas as espécies coloridas $\left(\mathrm{Cu}^{2+} \mathrm{e} \mathrm{Cr}_{2} \mathrm{O}_{7}{ }^{2-}\right)$, esquecendo-se dos contra-íons incolores $\left(\mathrm{SO}_{4}{ }^{2-} \mathrm{e} \mathrm{K}^{+}\right)$presentes nas respectivas soluções de origem.

A Figura 5 mostra ainda não haver diferenças significativas no desempenho dos alunos do curso médio e curso superior nas questões que envolvem a interpretação do que ocorre na interação das soluções com as resinas, durante a passagem da solução verde sucessivamente pelas duas colunas de resinas e na recuperação posterior das mesmas. O desempenho foi baixo, em parte porque o critério utilizado no levantamento das respostas para a construção da Figura 
5 foi rigoroso. Acertos parciais não foram considerados. Foi necessário então analisar os tipos de respostas, para avaliar o grau de compreensão dos alunos, quanto aos fenômenos ocorridos.

Passando-se a solução verde pela coluna de resina A e depois pela $\mathrm{B}$, os líquidos eluídos foram caracterizados pelas cores e determinação de $\mathrm{pH}$, no caso das turmas do $2^{\circ}$ e $3^{\circ}$ anos e FD. Para os alunos da FN, foram adicionadas, no data-show exibido, verificações de condutividade (Figura 2).

Pouquíssimos alunos conseguiram propor corretamente os íons presentes na solução eluída da coluna A, que se apresentou como um líquido alaranjado, ácido e condutor eletrolítico. Se forem computadas todas as respostas que mencionaram alguma espécie contendo cromo, representada corretamente ou não, as porcentagens elevam-se para $49 \%$ ( $2^{\circ}$ ano), $55 \%$ ( $3^{\circ}$ ano), $92 \%$ (FD) e $75 \%$ (FN). Entretanto as respostas, corretas ou não, que incluíram o íon $\mathrm{H}^{+}$como íon presente no eluído, foram em número muito menor, a saber, $25 \%$ ( $2^{\circ}$ ano), $27 \%$ ( $3^{\circ}$ ano), $9 \%$ (FD) e $6 \%(\mathrm{FN})$. Isso é preocupante, pois mostra que os alunos não utilizaram a informação sobre o pH da solução, restringindo-se a uma resposta parcial baseada na observação da cor. Conseqüentemente, não conseguiram também deduzir o que ocorreu na coluna de resina. Muitos explicaram a mudança de coloração de verde para alaranjado pela ação da resina $\mathrm{A}$ segurando o íon $\mathrm{Cu}^{2+}$, mas não perceberam que houve uma troca dos cátions $\mathrm{Cu}^{2+}$ e $\mathrm{K}^{+}$por íons $\mathrm{H}^{+}$, pois suas respostas especificavam eluído contendo os ânions sulfato e dicromato e também íons $\mathrm{K}^{+}\left(17 \%\right.$ no $2^{\circ}$ ano, $18 \%$ no $3^{\circ}$ ano, $39 \%$ na FD e $12 \%$ na FN). Falha no conceito de eletroneutralidade das soluções ficou também patente nesta questão, considerando a parcela de respostas em que eram mencionados apenas ânions, sem os cátions ( $8 \%$ no $2^{\circ}$ ano, $24 \%$ no $3^{\circ}$ ano, $35 \%$ na FD e $53 \%$ na FN).

Dificuldade semelhante foi encontrada na interpretação da passagem do eluído da coluna de resina A pela resina $\mathrm{B}$, da qual resultava um líquido incolor, neutro e não condutor. Os índices de acerto nesta questão, embora baixos, foram superiores aos da questão anterior, o que pode ser atribuído ao resultado do teste de condutividade. Mesmo assim, a observação da cor continuou sendo o fator decisivo, pois muitos alunos concluíram que a resina $\mathrm{B}$ segurava os íons dicromato, mas não perceberam que os íons sulfato também seriam retidos. Foi elevada a porcentagem de alunos que responderam que este eluído contém íons $\mathrm{K}^{+} \mathrm{e} \mathrm{SO}_{4}^{2-}$, ambos incolores (30\% do $2^{\circ}$ ano, $38 \%$ do $3^{\circ}$ ano, $61 \%$ da FD e $38 \%$ da FN).

A regeneração da resina $\mathrm{A}$, por tratamento com solução de $\mathrm{H}_{2} \mathrm{SO}_{4}$, forneceu um líquido azul e a da resina $\mathrm{B}$, utilizando solução de $\mathrm{NaOH}$, um líquido amarelo, conforme se observa na Figura 3. Novamente a maioria dos alunos se restringiu às colorações, não se empenhando em compreender o que ocorrera. Deve-se mencionar aqui que os alunos, que não consideraram os íons incolores presentes na solução verde, erraram também, como conseqüência, estas duas questões.

As porcentagens de alunos que interpretaram a solução azul como sendo de sulfato de cobre, ignorando o sulfato de potássio, foram de $49 \%$ ( $2^{\circ}$ ano), $45 \%$ ( $3^{\circ}$ ano), $61 \%$ (FD) e $62 \%$ (FN). Some-se a isso mais alguns que só mencionaram a presença do cobre, a saber, $5 \%$ ( $3^{\circ}$ ano), $30 \%$ (FD) e $16 \%$ (FN).

Já na solução amarela, as porcentagens de alunos que se restringiram ao dicromato de sódio, não incluindo o sulfato de sódio, foram $15 \%$ ( $2^{\circ}$ ano), $25 \%$ ( $3^{\circ}$ ano), $52 \%$ (FD) e $22 \%$ (FN). Se forem incluídas todas as respostas que mencionaram alguma espécie contendo cromo, formulada corretamente ou não, as porcentagens elevam-se para $47 \%$ ( $2^{\circ}$ ano), $47 \%$ ( $3^{\circ}$ ano), $95 \%$ (FD) e $81 \%$ (FN). Algumas destas respostas, completamente erradas, afirmaram a presença de dicromato de potássio nesta solução, provavelmente por associação com a solução alaranjada utilizada no início do experimento. Foram $28 \%$ ( $2^{\circ}$ ano), $9 \%$ ( $3^{\circ}$ ano), $10 \%$ (FD) e $32 \%$ (FN). Observe-se que a espécie presente neste meio alcalino é o cromato e não o dicromato, mas este conhe- cimento não foi exigido dos alunos, em virtude de não terem feito ainda disciplinas de Química Analítica.

A análise das respostas mostra ainda que estudantes do ensino médio, mas não os do ensino superior, deram respostas vagas (presença de íons positivos e íons negativos) ou então espécies absurdas para um meio aquoso, por exemplo, $\mathrm{NaH}, \mathrm{K}_{2} \mathrm{O}, \mathrm{O}^{2-}$. Além disso, alguns desses estudantes confundiram as cores das soluções com as do indicador universal, fazendo interpretações do tipo: amarelo $\mathrm{pH}$ 6, verde $\mathrm{pH}$ 7, azul pH 10.

\section{Parte II - Purificação de água utilizando as resinas A e B}

Esta parte do experimento repetia os procedimentos anteriores, utilizando, porém, um líquido incolor, denominado água impura, a qual foi passada sucessivamente por colunas contendo os dois tipos de resina. Ela não foi apresentada aos alunos do curso noturno da FCF, pela menor disponibilidade de tempo desta turma.

A questão 2 do relatório, solicitando a descrição das observações dos testes de condutividade do líquido, antes e após a passagem pelas resinas, visava verificar se os estudantes são capazes de separar a mera descrição dos fatos experimentais e a interpretação dos mesmos. As respostas indicaram que 55\% dos alunos do ensino superior fazem esta distinção, contra apenas 20 a 30\% dos alunos do ensino médio.

A questão seguinte, sobre a medida do $\mathrm{pH}$ desses líquidos, pode ser dividida em duas partes. Uma se refere ao valor obtido na medida, onde foi observado um acerto na faixa de 80 a $90 \%$ para os alunos do ensino superior e um acerto variando de 60 a $90 \%$ para os alunos do ensino médio. A outra parte diz respeito à interpretação dos valores de $\mathrm{pH}$. Aqui ficou realmente claro que, apesar de terem acertado os valores de $\mathrm{pH}$, os alunos, em sua maioria, independentemente do nível de formação, não conseguiram entender bem o funcionamento das resinas. Muitos se limitaram a afirmar a presença de $\mathrm{H}^{+}$no eluído da coluna $\mathrm{A}$ e o caráter neutro do eluído da coluna $\mathrm{B}$. Alguns imaginaram a ocorrência de uma reação química entre a resina A e espécies básicas presentes na solução. Outros supuseram que a resina A retém os íons $\mathrm{OH}^{-}$da água, aumentando por isso a concentração de íons $\mathrm{H}^{+}$, enquanto a resina $\mathrm{B}$ retém íons $\mathrm{H}^{+}$, ficando as resinas com excesso de cargas, o que revela uma completa falta de domínio do conceito de eletroneutralidade. Uma explicação correta dos equilíbrios de troca iônica foi fornecida por apenas $13 \%$ dos alunos do ensino superior, $7 \%$ dos alunos do $3^{\circ}$ ano e $12 \%$ dos alunos do $2^{\circ}$ ano do ensino médio.

Na questão sobre que espécies podem ser removidas pelas resinas, cerca de $40 \%$ dos alunos responderam corretamente. Várias respostas incorretas foram semelhantes às fornecidas nas explicações dos valores de $\mathrm{pH}$, ou seja, a resina $\mathrm{A}$ remove bases e a resina $\mathrm{B}$ remove ácidos.

Com relação à pergunta de como ficam as resinas após muito uso, cerca de $60 \%$ dos alunos do ensino superior e 35 a $40 \%$ dos alunos do ensino médio responderam que as mesmas ficam saturadas de íons e/ou se tornam ineficazes.

Quanto à recuperação das resinas, apenas 20 a 25\% dos alunos responderam corretamente, apesar desse processo ter sido ilustrado na apresentação do data-show sobre o uso de resinas, conforme se vê na Figura 3. É revelador observar que $25 \%$ dos alunos do $2^{\circ}$ ano do ensino médio e $31 \%$ dos alunos do $3^{\circ}$ ano responderam que as resinas podem ser recuperadas por lavagem com água.

\section{DISCUSSÃO DOS EXPERIMENTOS}

Após o término das demonstrações e entrega dos relatórios, foi possível discutir os experimentos com os alunos da FCF, porém não 
com os participantes da Olimpíada de Química, que tiveram outras atividades enquanto a banca examinadora corrigia e avaliava os relatórios para a sessão de distribuição das medalhas realizada no mesmo dia.

Por esta razão, a diretoria da Seção Regional de São Paulo da Associação Brasileira de Química, organizadora da Olimpíada, providenciou um material em compact-disc para ser distribuído às 400 escolas participantes, contendo as imagens dos experimentos, os gabaritos das respostas e uma seleção das melhores respostas redigidas pelos estudantes.

Na discussão efetuada com os alunos da FCF, foram comentadas as respostas e ministradas noções sobre resinas de troca iônica, abordando os tópicos:

a) a matriz polimérica, geralmente constituída por um copolímero de estireno e divinilbenzeno, sendo este último o responsável pela formação de ligações cruzadas ("cross-linking”), resultando numa rede tridimensional ${ }^{4,7-9}$;

b) o efeito do aumento do grau de reticulação, determinado pela porcentagem em mol de divinilbenzeno (de 5 a $12 \%$, mais comumente $8 \%$ ), conferindo, às resinas trocadoras, maior rigidez, menor solubilidade, porosidade e grau de entumescimento ${ }^{4,7,8}$;

c) a introdução de grupos sulfonatos (- $\mathrm{SO}_{3}^{-}$, neutralizados por cátions trocáveis) na estrutura do polímero, resultando em resina catiônica tipo poliestireno-divinilbenzeno sulfonada, sintetizada por d'Alelio em $1944^{4,5}$ e comercializada no ano seguinte pela Dow Chemical Co., com a marca registrada de "Dowex 50";

d) a introdução de grupos de amônio quaternário, por exemplo, $\mathrm{CH}_{2} \mathrm{~N}^{+}\left(\mathrm{CH}_{3}\right)_{3}$ (neutralizados por ânions trocáveis), formando uma resina aniônica, fortemente básica. A primeira resina deste tipo foi produzida por McBurney em $1946^{4}$ e lançada no comércio, por Rohm \& Haas Co., com a marca registrada de "Amberlite IRA-400";

e) os equilíbrios de troca de íons envolvendo resina catiônica, fortemente ácida, na forma $\mathrm{H}^{+}$(a resina A utilizada no experimento) e resina aniônica, fortemente básica, na forma $\mathrm{OH}^{-}$(a resina $\mathrm{B}$ ) e a obtenção e usos de água desionizada ${ }^{4,5,7,8,10}$;

f) os processos de regeneração das resinas ${ }^{4,7}$.

Nas duas partes do procedimento, usando a solução colorida ou a solução incolor, foi obtida água desionizada após a passagem pelas colunas de resinas A e B. A solução colorida é importante para ilustrar a reversibilidade dos processos de troca iônica. A solução incolor, denominada água impura, é uma solução $0,1 \mathrm{~mol} \mathrm{~L}^{-1}$ de cloreto de sódio, porém água do mar seria igualmente adequada e talvez até mais interessante.

Finalmente, cabe uma sugestão para quem se interessou em aproveitar as idéias contidas neste artigo e não dispõe das resinas. Elas podem ser obtidas a partir de cartuchos exauridos de desionizadores comerciais de leito misto, usados em purificação de água. Um procedimento simples e eficiente foi proposto por Kuya et al. ${ }^{11}$, para separar as resinas, catiônica e aniônica, constituintes do leito misto. Baseia-se na imersão da mistura em solução salina de densidade intermediária às das duas resinas, conforme ilustrado na Figura 6. A resina aniônica, menos densa, flutua neste meio. As densidades das resinas catiônicas fortemente ácidas e resinas aniônicas fortemente básicas situam-se nas faixas 1,18-1,38 e 1,07-1,12 $\mathrm{g} \mathrm{mL}^{-1}$, respectivamente ${ }^{4}$.

\section{CONCLUSÕES}

A análise das respostas revelou que um semestre de curso superior fez diferença, preparando melhor o aluno para reconhecer as espécies presentes nos sistemas e formulá-las corretamente. Essa

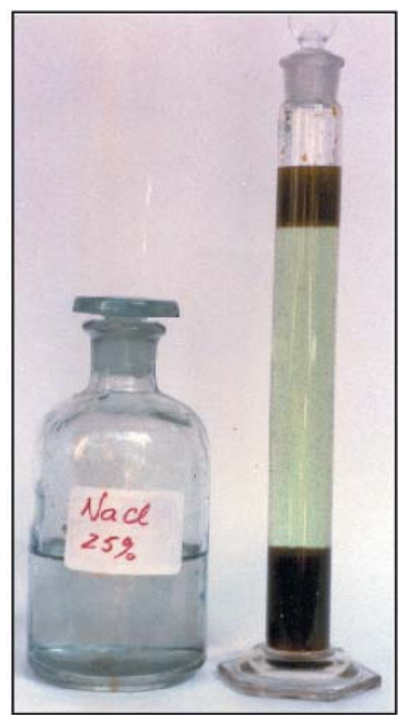

Figura 6. Separação de resinas catiônica e aniônica por diferença de densidade

diferença foi mais pronunciada nos alunos do período diurno, provavelmente por terem mais tempo e disposição para o estudo do que os do noturno, muitos dos quais chegam para as aulas depois de uma jornada de trabalho.

Já nas questões que exigiram associação de vários resultados, interpretação e proposta de explicação, o desempenho dos alunos foi decepcionante. Isso, porém, pode se transformar num trunfo. $\mathrm{O}$ valor didático da atividade reside justamente no elevado grau de motivação e interesse dos alunos para as explicações e discussões que se seguiram. Estas aulas, para 77 alunos e outra para 68 alunos, não tiveram nenhum dos problemas de disciplina e dispersão de atenção, por parte dos alunos, tão comuns em aulas expositivas tradicionais. A tendência em responder apenas parcial e superficialmente as questões, restringindo-se aos aspectos mais evidentes, ficou claramente demonstrada para cada aluno, servindo como um alerta para o seu comportamento futuro perante novos desafios.

\section{AGRADECIMENTOS}

As autoras agradecem à diretoria da Seção Regional de São Paulo da Associação Brasileira de Química, organizadora da Olimpíada de Química SP-2002, por ter permitido a consulta aos relatórios dos estudantes, bem como aos alunos da FCF que cursaram a disciplina QFL-138, no Instituto de Química, USP, em 2002, e aos colegas que ministraram essa disciplina. A. S. Maia agradece à FAPESP e ao Programa de Aperfeiçoamento de Ensino, PAE, da Pró-Reitoria de Pós-Graduação da USP.

\section{REFERÊNCIAS}

1. http://allchemy.iq.usp.br, acessada em Outubro 2002.

2. Thompson, H. S.; J. R. Agric. Soc. Engl. 1850, 11, 68; Way, J. T.; J. R. Agric. Soc. Engl. 1850, 11, 313; apud ref. 2, p. 2.

3. Kunin, R.; Ion Exchange Resins, $2^{\text {nd }}$ ed., Robert E. Krieger Publ. Co.: Huntington, 1972, cap. 1, p. 1 .

4. Dardel; F. de; Arden, T. V. Em Ulmann's Encyclopedia of Industrial Chemistry; Elvers, B.; Hawkins, S.; Ravenscroft, M.; Schulz, G., eds.; $5^{\text {th }}$ ed., VCH Publishers: New York, 1989, vol. A14, p. 393.

5. Raitt, J. G., ed.; Química - Intercámbio Iónico; Nuffield Foundation Special Study, Ed. Reverté: Barcelona, 1974.

6. Kuya, M. K.; Osorio, V. K. L.; Resumos da IX International Conference on Chemical Education, São Paulo, Brasil, 1987. 
7. Vogel, A. I.; Análise Química Quantitativa, revisto por Mendham, J.; Denney, R. C.; Barnes, J. D.; Thomas, M.; $6^{\mathrm{a}}$ ed., Livros Técnicos e Científicos Ed. S.A.: Rio de Janeiro, 2002, cap. 3, p. 44; Atkins, P.; Jones, L.; Chemistry - Molecules, Matter and Change; $2^{\mathrm{a}}$ ed., W. H. Freemann and Company: New York, 1997, cap. 20, p. 780

8. Giesbrecht, E., coord.; Experiências de Química; Ed. Moderna/EDUSP: São Paulo, 1982, cap. 24, p. 201.
9. Dickert, C. Em Kirk-Othmer Encyclopedia of Chemical Technology; Kroschwitz, J.; Howe-Grant, M., eds.; $4^{\text {th }}$ ed., John Wiley \& Sons: New York, 1995, vol. 14, p. 737.

10. Masterton, W.L.; Slowinski, E. J.; Química Geral Superior, $4^{\mathrm{a}}$ ed., Ed. Interamericana Ltda.: Rio de Janeiro, 1978, p. 268; Lee, J. D.; Química Inorgânica - não tão concisa, tradução da $5^{\mathrm{a}}$ ed. inglesa, Ed. Edgard Blücher Ltda: São Paulo, 1999, cap. 15, p. 285.

11. Kuya, M. K.; Matsumoto, F. M.; Kawashita, M. Y.; Quim. Nova 1990, 13, 205. 